\title{
Internalisasi Pendidikan Karakter Hindu Melalui Pembelajaran Bhagavad Gita Digital di Pasraman Gopisvara Buleleng
}

\author{
I Made Bagus Andi Purnomo \\ Sekolah Tinggi Agama Hindu Negeri Mpu Kuturan Singaraja \\ bagusandipurnomo@gmail.com
}

\section{Riwayat Jurnal}

Artikel diterima: 26 Juli 2018

Artikel direvisi: 20 Oktober 2018

Artikel disetujui: 2 November 2018

\begin{tabular}{|l|l|}
\hline Kata Kunci: & Abstrak \\
Pendidikan Karakter & Masalah karakter generasi muda kini mendapat banyak perhatian \\
Pasraman & dari berbagai pihak. Mulai dari menurunna nilai etika dan \\
moral, hingga semakin bertambahnya masalah pergaulan bebas. & Terlebih lagi, Bali dikenal sebagai kawasan wisata, di mana \\
orang-orang muda sangat dekat dengan perkembangan zaman \\
dan modernisasi yang cepat. Di sisi lain, sayangnya, pendidikan \\
agama yang ditujukan pada generasi muda umat Hindu di Bali \\
dianggap sangat rendah. Porsi pelajaran agama di sekolah masih \\
sangat terbatas sehingga diperlukan peningkatan pemahaman \\
agama melalui pola pasraman non-formal yang fokus pada \\
pendidikan karakter. Oleh karena itu, penelitian ini dilakukan \\
sebagai upaya untuk menginternalisasi pendidikan karakter \\
Hindu melalui pembelajaran Bhagavad Gita Berbasis Digital di \\
Pasraman Gopisvara Buleleng. Metode yang digunakan dalam \\
penelitian ini adalah metode kualitatif dengan menggunakan \\
pendekatan rasionalistik. Sementara itu, data dicari melalui \\
survei primer dan sekunder dengan tinjauan studi literatur. \\
Pengambilan sampel dilakukan dengan menggunakan metode \\
purposive sampling untuk mendapatkan responden yang \\
kompeten atau berpengaruh. Tujuan diperoleh dengan \\
menggunakan metode/metode analisis stakeholder.
\end{tabular}




\begin{tabular}{|l|l|}
\hline \multicolumn{1}{|l}{ Therefore, this research was conducted as an attempt to } \\
internalize Hindu character education through the learning of \\
Digital-Based Bhagavad Gita in Pasraman Gopisvara Buleleng. \\
The method used in this study is a qualitative method using a \\
rationalistic approach. Meanwhile, the data is carried out \\
through primary and secondary surveys with a review of \\
literature studies. The sampling was done by using purposive \\
sampling method to get competent or influential respondents. \\
The objectives were obtained by using the method/ method of \\
stakeholder analysis.
\end{tabular}

\section{Pendahuluan}

Masalah karakter di Indonesia semakin meresahkan. Berbagai kasus yang banyak dicatat di media sosial adalah bukti. Bukan hanya satu atau dua, bahkan ratusan. Belum menyelesaikan berbagai fenomena, pada awal tahun 2018 ada kasus siswa di Sampang Madura, Jawa Timur yang mencoreng potret pendidikan di tanah air karena membunuh gurunya sendiri. Ada banyak kasus lain yang sangat memprihatinkan tentang potret pendidikan di Indonesia.

Masalah pendidikan juga tidak terlepas dari filosofi pendidikan yang telah dilakukan di Indonesia. Pendidikan di Indonesia dianggap oleh banyak orang banyak mengacu pada pola pendidikan barat yang umumnya materialistis. Unsur-unsur etis dan moral tidak menjadi hal yang penting di barat dan pendidikan di barat bersandar pada akal (Donder, 2004, 64). Satya Sai Baba (dalam Donder, 64-65) mengungkapkan bahwa pendidikan harus membuat seseorang memiliki karakter yang baik, tetapi faktanya justru sebaliknya membuktikan bahwa pendidikan saat ini murni materialistik.

Seiring berjalannya waktu dan era mulai berkembang, nilai-nilai filosofis pendidikan di antara orang-orang, terutama siswa di sekolah, mulai menipis. Cita-cita yang diidealkan dan diharapkan dalam realitas berbanding terbalik dengan harapan dan kenyataan. Terbukti, ada banyak keluhan dari masyarakat tentang penurunan tata krama, etika dan kreativitas karena melemahnya pendidikan budaya dan karakter nasional (Dharmaningtyas, 2004: 34). Fakta dan data tersirat oleh kesimpulan bahwa saat ini ada krisis yang nyata dan mengkhawatirkan dalam masyarakat yang melibatkan properti paling berharga bangsa, yaitu anak-anak. Krisis termasuk peningkatan seks bebas, peningkatan tingkat kekerasan anak dan remaja, kejahatan terhadap teman, pencurian anak-anak, kecurangan, dan penyalahgunaan narkotika, pornografi dan kebiasaan bullying di sekolah. Nusa Bali Daily (2015: 4) menulis sejumlah anak di bawah umur yang tidak lain adalah siswa sekolah yang ditangkap oleh jam 
malam di asrama mereka dengan seorang rekan pria. Kasus ini adalah salah satu kasus berbagai kasus lain di Indonesia yang memperkuat kondisi yang ada degradasi moral pada anak-anak bangsa. Secara pragmatis, hasil penelitian ini diharapkan dapat bermanfaat sebagai acuan untuk menerapkan konsep pendidikan karakter kepada siswa dari berbagai jenjang pendidikan. Apalagi saat ini sangat diperlukan berbagai penelitian tentang pendidikan karakter untuk menemukan rumusan yang tepat mengenai pendidikan di negara tersebut. Pendidikan karakter berbasis budaya adalah salah satu alat untuk melahirkan anak muda yang memiliki etika dan daya juang. Mereka akan menjadi sejarah masa depan bangsa jika mereka mampu menjadi generasi yang cerdas dan kompetitif.

Seiring dengan program pelaksanaan revolusi mental oleh pemerintah pusat. Berbagai jenis pasraman Hindu baik di Bali maupun di luar Bali yang menekankan pendidikan karakter guna menghasilkan keluaran (output) siswa yang berkualitas, kepribadian dan daya saing. Peraturan Menteri Agama RI (PMA) Nomor 56 tahun 2014 tentang pendidikan agama Hindu dalam Pasal 1 menyatakan bahwa pendidikan agama Hindu adalah jalur pendidikan formal dan non-formal dalam wadah pasraman. Ancaman formal menurut PMA adalah jalur pendidikan terstruktur dan berjenjang yang terdiri dari pendidikan dasar, pendidikan menengah dan pendidikan tinggi.

Mengenai Pasraman lebih dalam, munculnya berbagai jenis pasraman dan kelompok spiritual di Pulau Dewata disebabkan oleh beberapa faktor. Beberapa dari mereka adalah Bali sebagai salah satu daerah di Indonesia dengan mayoritas pengikutnya mengikuti agama Hindu dan juga memiliki pariwisata yang berkembang pesat. Jadi ada ketertarikan ganda di mana banyak orang dari seluruh dunia datang ke Pulau Dewata. Pertama, bisa melakukan perjalanan, kedua, apa yang juga terjadi dengan perkembangan pasraman adalah menenangkan jiwa dengan wisata spiritual atau lebih dikenal dengan istilah "retret". Salah satu pasraman informal di Bali yang telah dikenal di Indonesia bahkan di beberapa negara seperti India, Rusia, Eropa dan Amerika Serikat adalah Pasraman Gopisvara di Desa Banyuning, Kabupaten Buleleng. Pasraman ini adalah salah satu dari pasraman bhakti yoga atau pasraman yang lebih menekankan pada pemujaan Tuhan Yang Maha Kuasa dengan segala manifestasinya berdasarkan ajaran Bhakti. Pasraman Sri Gopisvara menekankan ajaran Bhagawad Gita. Pancama Veda dianggap sebagai sumber sastra otentik dalam literatur sastra Veda yang menggambarkan pentingnya bhakti yoga. Bhagawad Gita Bab 12 Sloka 8 (Prabhupada: 2000: 619) menggambarkan ajaran pelayanan bakti dalam Veda sebagai berikut. 


\section{mayy eva di mana ädhatsva \\ mayi buddhià niveçaya \\ nivasiñasi mayy eva \\ ata ürdhvaà na saàçayaù}

Terjemahan:

Pusatkan pemikiranmu pada-Ku, Personalitas Tertinggi Tuhan Yang Maha Esa dan gunakan semua kecerdasanmu dalam diri-Ku, dengan cara ini Anda akan selalu hidup di dalam Aku, tanpa keraguan.

Dalam ayat lain di bab yang sama, Bab 8 (Prabhupada, 2000: 623) juga dijelaskan tentang kebajikan yoga bhakti. Ayat ini paling sering dikutip dalam hal menunjukkan kebaktian sebagai jalan menuju Ketuhanan. Tidak hanya itu, ayat ini menunjukkan kebajikan pelayanan bakti terhadap kesempurnaan hidup dan tertuang dalam sloka berikut.

\section{kamu tu dharmämåtam idam yathoktaà paryupäsate çraddadhänä mat-paramä bhaktäs te 'téva me priyäù}

Terjemahan:

Aku mencintai mereka yang mengikuti jalan pengabdian abadi ini, sepenuhnya rajin beriman dan menjadikan-Ku tujuan tertinggi.

Selain di pasraman, dengan model pendidikan asram yang berbasis Bhakti Yoga dan di Bali sendiri, kini ada berbagai jenis pernikahan nonformal yang mulai dicari oleh masyarakat. Pasraman nonformal adalah perwujudan dari konsep gurukula atau proses pendidikan Hindu kuno di mana afiliasi Indonesia menjadi model katyagan atau padepokan. Tidak hanya itu, pendidikan karakter adalah salah satu program penting pemerintah dalam upaya mewujudkan generasi masa depan yang handal dan mampu bersaing secara global. (Sandika, 2014: 109). Salah satu model pembelajaran yang menarik adalah ajaran Bhagawad Gita menggunakan model aplikasi. Pembelajaran ini sangat menarik, meskipun hanya diterapkan dalam pengaturan non-formal. Tapi, dampaknya pada siswa sangat besar. Mereka (siswa pasraman) sangat termotivasi untuk menjelajahi Bhagawad Gita dimanapun dan kapanpun.

\section{Pembahasan}

Penelitian ini dilakukan sebagai upaya untuk menginternalisasi pendidikan karakter Hindu melalui pembelajaran Bhagavad Gita berbasis digital di Pasraman Gopisvara Buleleng. Metode yang digunakan dalam penelitian ini adalah pendekatan kualitatif dan rasionalistik. 
Sementara itu, data dilakukan melalui survei primer dan sekunder dengan tinjauan studi literatur. Pengambilan sampel dilakukan dengan menggunakan metode purposive sampling untuk mendapatkan responden yang kompeten atau berpengaruh. Tujuannya diperoleh dengan menggunakan analisis pemangku kepentingan.

Masyarakat Indonesia saat ini sangat dekat dengan teknologi informasi (internet). Setiap aktivitas komunitas tidak dapat dipisahkan dari teknologi (gadget). Fenomena ini memiliki dampak signifikan pada sistem kehidupan masyarakat. Banyak ahli kemudian menyebutkan bahwa perkembangan pesat lebih dikenal sebagai era disrupsi. Disrupsi adalah fenomena ketika orang menggeser kegiatan yang awalnya dilakukan di dunia nyata ke dunia maya. Fenomena ini berkembang dalam pola perubahan dunia bisnis. Munculnya transportasi gadget adalah salah satu efek paling populer di Indonesia.

Era disrupsi menjadi kendala dan keuntungan bagi pelaku bisnis di Indonesia. Karena era disrupsi juga digunakan sebagai era digitalisasi, dimana semua kegiatan/ kegiatan menggunakan media Digital atau internet. Ini membuat pemimpin bisnis atau pemimpin pasar harus pintar mencari celah atau solusi tentang bagaimana menjadikan era gangguan ini sebagai keuntungan bagi mereka. Pembelajaran konteks digital kini mulai menyentuh ranah agama. Banyak model sastra Hindu digital yang beredar di masyarakat. Sastra digital ini muncul guna memberikan akses kemudahan kepada masyarakat untuk membelajari sastra lebih sederhana dan dengan waktu yang efektif dan efesien.

Pembelajaran konsep digital dengan menggunakan gadget juga dinilai sangatlah efektif dan menyenangkan. Pengguna akan sangat mudah mengakses sloka yag ada dalam Bhagavad Gita digital tersebut. Selain mudah, juga sangat mudah dalam menyimpan slokasloka yang ada diaplikasi tersebut. Dengan berbagai kemudahan pembelajaran dapat menstimulasi siswa untuk semakin gita mendalami Bhagawad Gita.

Pasraman Gopisvara Buleleng menggunakan pembelajaran Bhagavad Gita berbasis digital untuk mempermudah pencarian sloka dan penjelasan. Bhagawad Gita Digital membantu siswa dalam pasraman untuk memahami presentasi sloka melalui pencarian dan penjelasan yang valid dan terarah. Program ini dianggap sangat baik untuk meningkatkan pemahaman ajaran agama Hindu di Gita. Salah satu ajaran penting tentang pendidikan karakter dalam bab 16 adalah Bhagavad Gita.

\section{Internalisasi Karakter Religius}

Sikap religius adalah salah satu tahapan awal menuju jalan Bhakti dalam arti yang sebenarnya kepada Tuhan Yang Maha Esa. Tahapan awal dilakukan dalam berbagai kegiatan 
dalam sadhana spiritual. Sangat ketat dan dengan semua aturan dan peraturan yang sangat mengikat. Maka dengan itu, perlahan pemurnian kehidupan akan muncul. Di situlah proses devosional baru saja dimulai.

Agama ditafsirkan sebagai adagium patuh pada ajaran dan secara teratur menerapkan ajaran-ajaran ini dalam kehidupan sehari-hari. Hinduisme mengakui dua jenis konsep penting dalam ajaran agama. Jnana dan Wijnana. Jnana dipahami sebagai pengetahuan yang hanya dikenal lebih dalam dari Wijnana, yaitu pengetahuan yang telah direalisasikan. Sikap religius disimpulkan untuk diwujudkan melalui pola belajar Bhagavad Gita secara teratur di pasraman.

\section{Internalisasi Karakter Disiplin}

Disiplin adalah usaha untuk menanamkan nilai sehingga subjek memiliki kemampuan untuk mematuhi aturan. Disiplin dapat menjadi istilah pengganti untuk instrumen dimana dapat dilakukan pada diri sendiri atau orang lain. Disiplin diri mengacu pada pelatihan yang diperoleh seseorang untuk memenuhi tugas tertentu atau untuk mengadopsi pola perilaku tertentu, meskipun orang itu lebih mungkin melakukan sesuatu yang lain.

Misalnya, seseorang mungkin tidak melakukan sesuatu yang menurutnya memuaskan dan menyenangkan dengan membelanjakan uangnya untuk sesuatu yang dia inginkan dan menyumbangkan uangnya ke organisasi amal dengan pemikiran bahwa itu lebih penting. Secara etimologis disiplin berasal dari bahasa latin "disibel" yang artinya pengikut. Seiring dengan perkembangan zaman, kata tersebut telah berubah menjadi "discipline" yang berarti kepatuhan atau terkait dengan ketertiban (wikipedia, diakses pada 1 Oktober 2018).

Sistem pendidikan brahmacari/ siswa yang sangat diprioritaskan adalah pengendalian pikiran, karena proses pendidikan menurut sistem brahmacari/ siswa tidak hanya mengasah kecerdasan rasio, tetapi memperkuat nilai-nilai budaya dan agama. Bukan hanya menjunjung tinggi peradaban pemikiran manusia untuk menciptakan objek material yang mewah dan canggih, tetapi mengembangkan keterampilan, memperluas wawasan pemikiran proporsional yang perspektif untuk menyampaikan pengetahuan terhadap nilai-nilai kebajikan ilahi dan manusia.

Konsep ajaran agama Hindu tentang lima jenis kejujuran, yaitu dikenal sebagai Panca Satya. Panca dan Satya. "Panca" berarti lima dan "Satya" berarti setia, jujur, dan bertanggung jawab dengan cara yang disebut sebagai kebenaran yang akan membawa orang ke kedamaian. Satya yang merupakan unsur kebenaran dan kejujuran menjadi sifat dan sifat Tuhan sebagai bagian dari sraddha. Dan seperti yang dijelaskan dalam Panca Satya, 
dinyatakan bahwa "kesetiaan, kejujuran dan tanggung jawab" dalam hidup sangat penting karena dengan satya kita dapat memperoleh kepercayaan yang mungkin tidak semua memilikinya.

Loyalitas muncul bukan dari orang lain, kesetiaan muncul dari diri kita sendiri, jadi bagaimana kita memupuk kesetiaan itu yang terdiri dari lima bentuk kesetiaan, kejujuran dan tanggung jawab. Lima bagian dari Lima Prinsip adalah sebagai berikut: (1) Satya Wacana, setia, jujur dan benar dalam berbicara. Jangan mengucapkan kata-kata kasar yang disebut "wak purusya". (2) Satya Hredaya, setia pada kebenaran dan kejujuran hati nurani, tegas berpendapat, dan tidak terombang-ambing. (3) Satya Laksana, setia dan jujur dalam mengakui dan bertanggung jawab atas kebenaran semua perbuatan yang telah dilakukan. (4) Satya Mitra, setia dan jujur dengan teman-teman dalam segala hal, dan berusaha untuk mengarahkan semua tindakan atau tindakan untuk selalu didasarkan pada kebenaran sesuai dengan ajaran agama. (5) Satya Samaya setia dan jujur tentang janji-janji yang telah dinyatakan dan memenuhi segala sesuatu yang disebabkan oleh pernyataan janji (www.phdi.com/feel kejujuran yang diakses pada 23 Oktober 2018).

\section{Internalisasi Karakter Ketenangan}

Ketenangan adalah salah satu hal yang paling dicari dalam kehidupan saat ini. Banyak orang kini sibuk mencari ketenangan karena merasa terlalu sibuk mengurus berbagai jenis pekerjaan di dunia material ini. Banyak yang stres dan bingung karena begitu banyak beban. Beban masalah pribadi, pekerjaan, masalah keluarga dan masalah lainnya. Banyak yang kemudian mencari cara spiritual mencari kedamaian dan kedamaian dalam hidup mereka. Mulai dari mengambil yoga, kelas meditasi dan sebagainya. Ini adalah salah satu cara untuk melepaskan pikiran dari berbagai masalah yang begitu mengikat.

Bentuk pendidikan karakter Hindu memberikan pembelajaran bagi para bakta dan siswa bagaimana menemukan solusi untuk menemukan kedamaian. Ketenangan adalah salah satu hal yang paling dicari dalam kehidupan saat ini. Banyak orang kini sibuk mencari ketenangan karena merasa terlalu sibuk mengurus berbagai jenis pekerjaan di dunia material ini. Banyak yang stres dan bingung karena begitu banyak beban. Cara kuat yang dilakukan orang Pasraman sehingga suasana hati yang tenang muncul adalah melakukan yoga dengan fokus pada kaki padma Tuhan Yang Maha Esa.

\section{Internalisasi Karakter Kedermawanan Sosial}

Kedermawanan sosial dalam kehidupan di pasraman yakni sifat kemurahan hati. Hal ini diyakini merupakan ciri utama seseorang yang telah maju dalam spiritualitas. 
Kedermawanan sosial pada tingkat spiritual ditafsirkan sebagai sikap belas kasih dan cinta di antara semua jenis makhluk hidup. Terutama terhadap sesama manusia yang membutuhkannya. Kemurahan hati juga sering diidentifikasikan dengan bermurah hati kepada mereka yang benar-benar membutuhkan bantuan atau bantuan dalam kehidupan mereka. Salah satu sifat ini (kedermawanan) adalah salah satu tujuan dalam proses mengajar di Pasraman di mana diharapkan bahwa kasih sayang dan cinta akan muncul di hati orang pasraman dengan membiasakan diri menjadi dermawan.

\section{Simpulan}

Pasraman Gopisvara Singaraja adalah salah satu model pendidikan pasraman bhakti yoga berbasis dan di Bali sendiri, sekarang ada berbagai jenis pernikahan non-formal yang mulai dicari oleh masyarakat. Salah satu model pembelajaran yang menarik adalah ajaran Bhagavad Gita menggunakan model aplikasi. Pembelajaran ini sangat menarik, meskipun hanya diterapkan dalam pengaturan non-formal. Tapi, dampaknya pada siswa sangat besar. Mereka (siswa pasraman) sangat termotivasi untuk menjelajahi Bhagawad Gita dimanapun dan kapanpun. Pembelajaran Bhagavad Gita Digital adalah pembelajaran yang menggunakan gadget dalam setiap proses pembelajaran. Mempelajari model ini menginternalisasi beberapa karakter. Karakter dinyatakan dalam Bhagavad Gita sendiri. Karakternya religius, disiplin, tenang dan kedermawanan secara sosial.

\section{Daftar Pustaka}

Dharmaningtyas. (2004). Pendidikan Yang Memiskinkan. Jakarta: Ganeca Press.

Donder, I. K. (t.thn.). Sisya Sista, Pedoman Menjadi Siswa Mulia. Surabaya: Paramitha. kemenag.go.id/ Ditjen Bimas Hindu. (2018, Oktober 18). Diambil kembali dari PMA 56 Sistem Pendidikan HIndu.

Nusa Bali.com/ kenalan remaja makin marak. (2018, Oktober 18).

Prabhupada, A. B. (2009). Bhagavad Gita At It Is. Jakarta: Hanuman Sakti.

Sandika, I. K. (2014). Menjadikan Generasi Muda Hindu Cerdas Berkarakter. Surabaya: Paramitha.

www.phdi.com/feel honesty. (2018, Oktober 23). 